Cite this: Org. Biomol. Chem., 2013, 11, 4516

Received 20th March 2013,

Accepted 13th May 2013

DOI: $10.1039 / \mathrm{c} 3 \mathrm{ob} 40919 \mathrm{~h}$

www.rsc.org/obc

\section{Aerobic C-H amination of tetrahydrocarbazole derivatives via photochemically generated hydroperoxides $t$}

\author{
Naeem Gulzar and Martin Klussmann* \\ A Brønsted acid catalyzed C-H functionalization via Intermediate PeroxideS (CHIPS), generated photo- \\ chemically, allows the oxidative coupling of indole derivatives with a variety of nitrogen nucleophiles. \\ The reaction can be performed in one pot and requires only visible light, elemental oxygen, a Brønsted \\ acid and a photosensitizer. The method can be applied to an efficient synthesis of some biologically \\ active compounds.
}

\section{Introduction}

The functionalization of $\mathrm{C}-\mathrm{H}$ bonds is an important and long standing goal in organic chemistry. ${ }^{1}$ Under oxidative conditions, a $\mathrm{C}-\mathrm{H}$ bond can be activated and coupled with different molecules to form $\mathrm{C}-\mathrm{C}$ and $\mathrm{C}$-heteroatom bonds, respectively. ${ }^{2}$ Such oxidative coupling reactions help to streamline the synthesis by saving steps, time and material and are thus attractive for green chemistry. ${ }^{3}$ But often the requirement for stoichiometric amounts of synthetic oxidants, expensive reagents or harsh conditions diminishes the overall sustainability of the method.

Autoxidation reactions occur frequently in nature and can functionalize $\mathrm{C}-\mathrm{H}$ bonds by introducing a hydroperoxide moiety. ${ }^{4}$ These processes can be highly useful, for example in the industrial oxygenation of hydrocarbons, but are also perceived as unwanted if they lead to decomposition or if they generate dangerously explosive compounds like ether peroxides. Recently, we discovered an oxidative coupling reaction that forms new $\mathrm{C}-\mathrm{C}$ bonds without the need for a redox-active catalyst, a representative example being the coupling of xanthene with cyclopentanone (Scheme 1a). ${ }^{5}$ The product is formed by simply stirring the substrates under air or oxygen in the presence of catalytic amounts of methanesulfonic acid. The reaction is believed to proceed by an autoxidation via intermediate peroxides like 1 . Inspired by this mechanistic

Max-Planck-Institut für Kohlenforschung, Kaiser-Wilhelm-Platz 1, 45470 Mülheim an der Ruhr, Germany. E-mail: klusi@mpi-muelheim.mpg.de; Fax: (+49) 208-306-2980; Tel: (+49) 208-306-2453

$\dagger$ Electronic supplementary information (ESI) available: Further optimisation studies, detailed experimental methods and product characterisation data including crystallographic analysis. CCDC 914987, 914988, 915538 and 915539. For ESI and crystallographic data in CIF or other electronic format see DOI: 10.1039/c3ob40919h
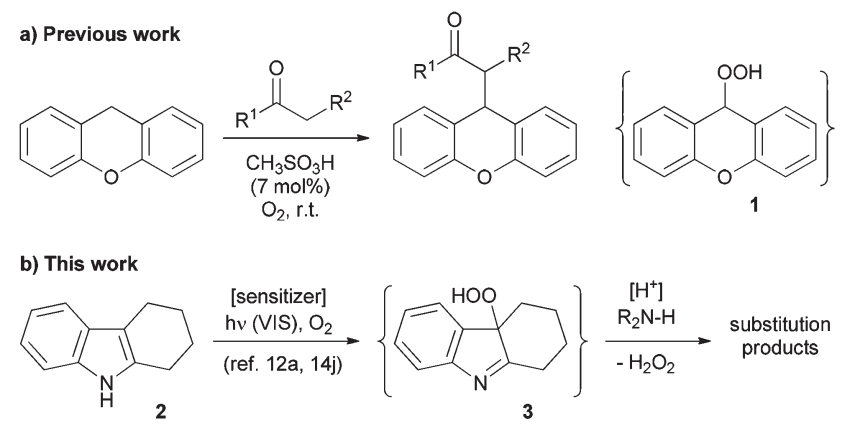

Scheme 1 C-H functionalization via Intermediate PeroxideS (CHIPS): (a) autoxidative coupling via suggested intermediate $\mathbf{1}$ (ref. 5a); (b) $\mathrm{C}-\mathrm{H}$ amination of indole derivatives by Brønsted acid catalyzed nucleophilic substitution via photochemically generated hydroperoxides.

rationale, we attempted to intentionally design similar reactions for the $\mathrm{C}-\mathrm{H}$ functionalisation via Intermediate Peroxides (CHIPS), ${ }^{6}$ which would give access to synthetically valuable products in a sustainable manner. As in the model reaction with xanthene, such reactions should optimally require only oxygen as the reagent and otherwise simply catalysts to facilitate the autoxidation and substitution of the peroxide group. ${ }^{7}$

In general, hydroperoxides are sensitive compounds and prone to $\mathrm{O}-\mathrm{O}$ bond cleavage, requiring the right choice of catalyst to prevent these undesired reactions while facilitating the desired $\mathrm{C}-\mathrm{O}$ bond cleavage and thus substitution with the desired reactant. Peroxides are known to rearrange in the presence of acid, a process that is industrially used in the synthesis of phenol and acetone via cumyl hydroperoxide, also known as the Hock phenol synthesis. ${ }^{8}$ On the other hand, it has been shown that the selectivity of $\mathrm{O}-\mathrm{O}$ versus $\mathrm{C}-\mathrm{O}$ bond cleavage in reactions with cumyl hydroperoxide can be controlled by a Lewis acid. ${ }^{9}$ Similar nucleophilic substitution reactions of 
peroxides have also been reported for a few other compounds. ${ }^{6,7,10}$

Indoles constitute a large number of biologically active compounds $^{11}$ and they are known to form peroxides by autoxidation in air. ${ }^{12}$ For synthetic purposes, indole hydroperoxides can be easily synthesized by reaction with singlet oxygen, which can be generated by photochemical methods, using a sensitizer and visible light. ${ }^{13}$ These hydroperoxides have been used in organic synthesis for further transformations like reductions or rearrangements, but apparently never for direct substitution reactions. ${ }^{14}$ Based on our previous experiences with the oxidative $\mathrm{C}-\mathrm{H}$ functionalization of xanthene mentioned above, we investigated various Brønsted acids for the substitution of the hydroperoxide group in compounds like 3, derived from indole derivatives 2 by the action of singlet oxygen (Scheme 1b).

\section{Results and discussion}

We started with tetrahydrocarbazole 2 as a test substrate, which can be easily oxidized to the corresponding hydroperoxide 3 by irradiation with visible light in the presence of elemental oxygen and a sensitizer like rose bengal. ${ }^{12 a, 14 j}$ Amino-derivatives of 2 are interesting synthetic targets due to their pharmaceutical activity. ${ }^{11 a, b, 15}$ We screened various $\mathrm{N}-\mathrm{H}$ nucleophiles and acid catalysts to facilitate a substitution reaction of the hydroperoxide moiety in 3 . These initial studies revealed $p$-nitroaniline to be a suitable nucleophile and trifluoroacetic acid as the best catalyst (see the ESI $\dagger$ for optimization details). A high yield of $86 \%$ of product 4 was achieved in methanol with a catalyst loading of $10 \mathrm{~mol} \%$ (Table 1, entry 1, method A). The new $\mathrm{C}-\mathrm{N}$ bond was selectively formed in the 1-position of the saturated ring as revealed by NMR spectroscopy and X-ray crystallography of selected products (see the ESI ${ }^{\dagger}$ for details) and in accordance with previous observations of related coupling reactions. ${ }^{14 j, 16}$ The reaction did not require an excess of one reagent and was completed within two hours at ambient temperature.

Table 1 Choice of reaction conditions depending on the electronic nature of the aniline nucleophile ${ }^{a}$

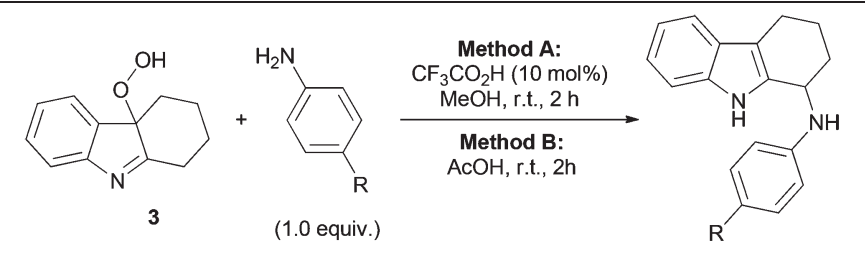

\begin{tabular}{lllll}
\hline Entry & $\mathrm{R}$ & Product & Method A yield (\%) & Method B yield (\%) \\
\hline 1 & $\mathrm{NO}_{2}$ & $\mathbf{4}$ & 86 & 30 \\
2 & $\mathrm{CN}$ & $\mathbf{5}$ & 80 & 80 \\
3 & $\mathrm{H}$ & $\mathbf{6}$ & 10 & 60
\end{tabular}

${ }^{a}$ Method A: 3 (0.5 mmol), aniline $(0.5 \mathrm{mmol}), \mathrm{CF}_{3} \mathrm{CO}_{2} \mathrm{H}(0.05 \mathrm{mmol})$, MeOH (0.5 ml), r.t., 2 h; Method B: $3(0.5 \mathrm{mmol})$, aniline $(0.5 \mathrm{mmol})$, $\mathrm{AcOH}(0.5 \mathrm{ml})$, r.t., $2 \mathrm{~h}$; isolated yields given.
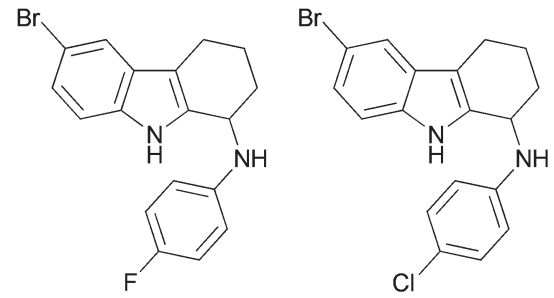

26, $70 \%$

$25,55 \%$

$\mathrm{HPV} \mathrm{IC}_{50}=<10 \mathrm{~nm}$

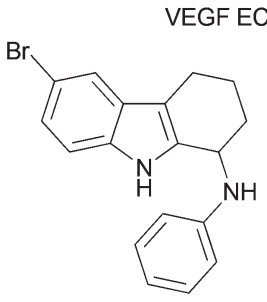
$C_{50}=<10 \mathrm{~nm}$

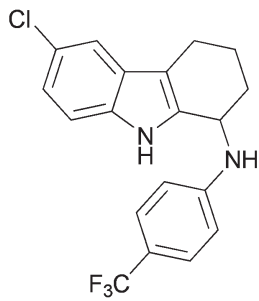

$27,68 \%$

VEGF $\mathrm{EC}_{50}=<10 \mathrm{~nm}$ $\mathrm{HPV} \mathrm{IC} \mathrm{C}_{50}=<10 \mathrm{~nm}$

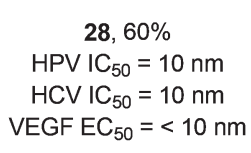

Fig. 1 Reported pharmaceutical activities of compounds synthesized according to method B (see Table 1 for the conditions). HPV: activity against human papilloma virus, see 18a. VEGF: inhibition of vascular endothelial growth factor, see 18c. HCV: activity against hepatitis C virus, see $18 b$.

Using this method, good yields were obtained with anilines having strongly electron withdrawing groups, but poor yields with aniline. The problem could be solved by using acetic acid as the solvent without any additional catalyst: aniline gave $10 \%$ isolated yield of coupling product 6 in methanol with trifluoroacetic acid, but $60 \%$ in acetic acid (Table 1, entry 3 ). In general, the use of acetic acid as the solvent (method B) was found to be most suitable for the reaction with aniline, halogen substituted anilines and indole derivatives without an annulated ring (e.g. products 18, 23-26 and 28, see Scheme 4 and Fig. 1 below), while the use of methanol and trifluoroacetic acid (method A) was better for the coupling with more electron poor anilines. Anilines bearing electron donating groups did not react, nor did amides or aliphatic amines. For anilines having a cyano, ester or carbonyl group, both methods work equally well (Table 1, entry 2, see also products 13 and 19 below).

In principle, hydroperoxide 3 can be conveniently prepared according to literature procedures. ${ }^{12 a, 14 j}$ Irradiating a homogeneous solution of $\mathbf{2}$ in toluene under an atmosphere of oxygen in the presence of rose bengal with visible light - either using a lamp or simply sunlight - leads to precipitation of the pure hydroperoxide. This material can be conveniently isolated by filtration and be directly employed in the substitution reaction, a procedure that was used for most of our studies (Scheme 2a). Alternatively, the solvent of the oxidation reaction can be removed under vacuum and the resulting mixture can be used in the next step without impairment of the yield in the final product (Scheme $2 \mathrm{~b}$ ). In order to provide an efficient onepot method for the conversion of tetrahydrocarbazole to the desired coupling products without the need to change solvents, we also investigated the photooxidation in methanol. A screening of several photosensitizers revealed phthalocyanine to be suitable, giving hydroperoxide 3 in quantitative 

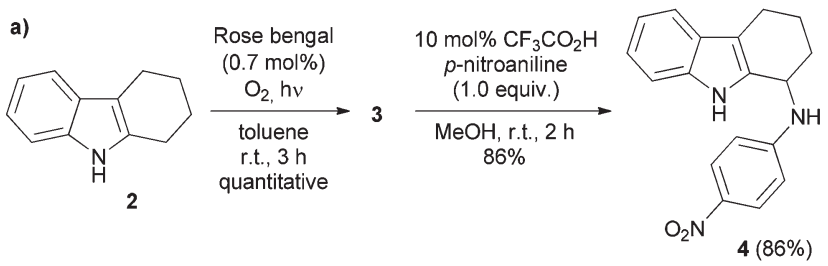

b)

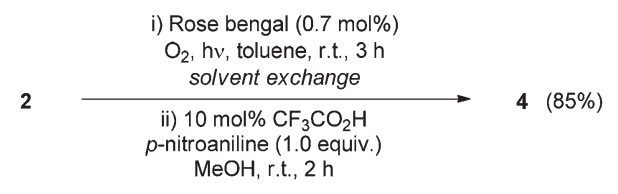

c)

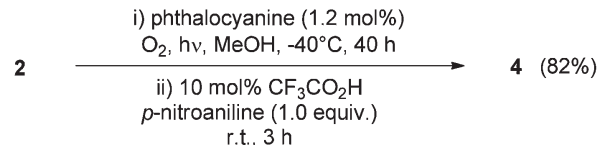

Scheme 2 Development of one-pot methods without isolation of hydroperoxide intermediate 3; (a) a two-step method with isolation of 3; (b) a one-pot method with solvent exchange; (c) a one-pot method without solvent exchange.

yield after a reaction time of 40 hours at $-40^{\circ} \mathrm{C}$. Addition of aniline and acid catalyst to this mixture then provides the coupling product $\mathbf{4}$ in essentially unchanged yield (Scheme 2c).

Accordingly, amination of the indole-derivatives described below can be performed in a one-pot, two-step method without the need to change the reaction solvent, except for the cases where acetic acid is used as the solvent for the coupling step. In all cases, the reaction does not require any aqueous workup. The solvent is directly evaporated after the completion of the reaction and the crude product is purified by column chromatography. In many cases, the product precipitates in pure form during the reaction and no chromatography is needed.

The product scope of the reaction between a wide range of aniline derivatives having electron withdrawing substituents and tetrahydrocarbazole hydroperoxides is shown in Scheme 3. Substituents in the tetrahydrocarbazole unit were well tolerated (e.g. products $\mathbf{7 - 9}, \mathbf{1 4 - 1 6}$ ) as were various anilines, indoline and tetrahydroquinoline nucleophiles (e.g. products 10-13). Saccharin, being acidic itself, afforded the coupling product 17 without the need for an additional acid catalyst. The reaction of 3-methyl- and 3-phenyl-tetrahydrocarbazole hydroperoxides with anilines resulted in the formation of diastereomeric mixtures of products 14-16, with diastereomer ratios ranging from $91: 9$ to $65: 35$. The major diastereomers for $\mathbf{1 5}$ and $\mathbf{1 6}$ were purified by column chromatography and the relative configuration of the alkyl group and aniline residue was determined as trans by ${ }^{1} \mathrm{H}-\mathrm{NMR}$ spectroscopy (see the ESI $\dagger$ ).

Scheme 4 and Fig. 1 show the coupling products with less electron deficient anilines or with more sensitive indole derivatives, using method B. Halogenated anilines generally gave better yields under these conditions, for example products 18, 25 and 26. The presence of the annulated saturated six membered ring is not necessary for the coupling reaction;
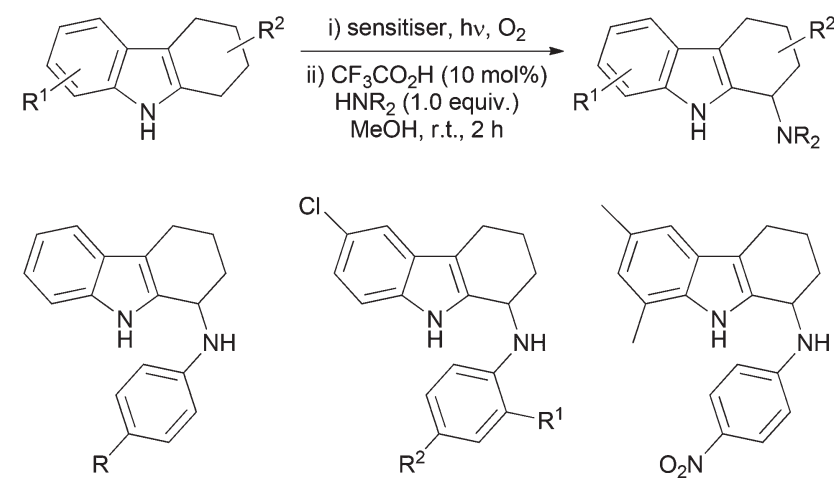

$\mathrm{Cl}$
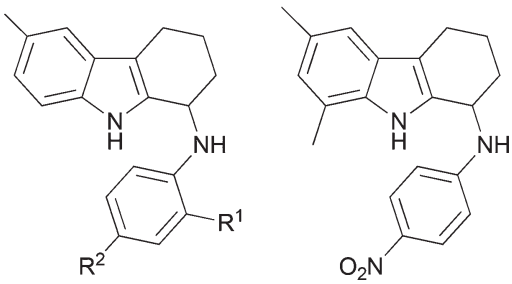

$\mathrm{R}=\mathrm{NO}_{2}, 4,86 \%$

$\mathrm{R}=\mathrm{CN}, \mathbf{5}, 80 \%$

$\mathrm{R}^{1}=\mathrm{H}, \mathrm{R}^{2}=\mathrm{NO}_{2}, 7,85 \%$

$\mathrm{R}^{1}=\mathrm{NO}_{2} \mathrm{R}^{2}=\mathrm{H}, 8,55 \%$

9, $86 \%$
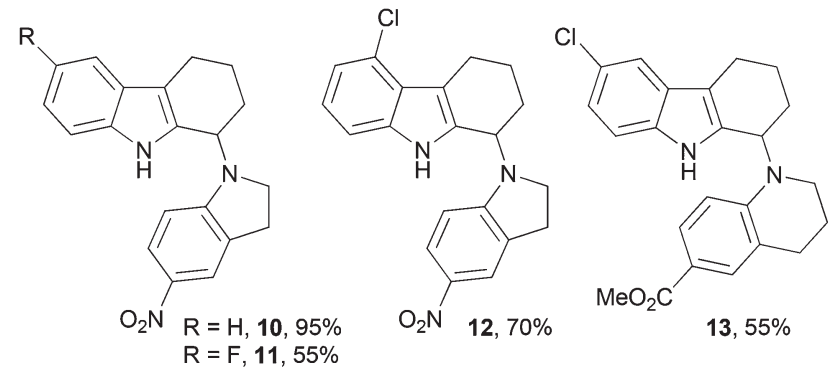

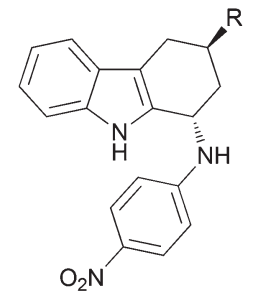

$\mathrm{R}=\mathrm{Me}, \mathbf{1 4}$, dr 83:17, 67\% $\mathrm{R}=\mathrm{Ph}, 15$, dr $91: 09,67 \%$

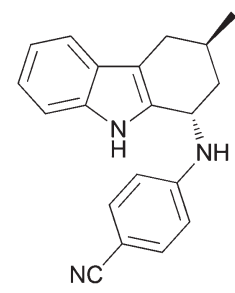

16, dr $65: 35,80 \%$

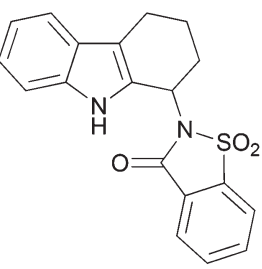

$17,52 \%[a]$
Scheme 3 Product scope of the reaction using method A (see Table 1 for the conditions). [a] Without the use of $\mathrm{CF}_{3} \mathrm{CO}_{2} \mathrm{H}$.

the reaction could also be performed successfully with 2,3dialkyl substituted indoles. It was not possible to form the corresponding hydroperoxide from 2,3-dimethyl indole; however, the hydroperoxides from 2-benzyl,3-methylindole and 2-propyl,3-ethylindole could be synthesized at ambient temperature or more reproducibly at $-40{ }^{\circ} \mathrm{C}$. The coupling products with $p$-cyanoaniline, 23 and $\mathbf{2 4}$, were formed in $67 \%$ and $60 \%$ yield, respectively. Indole derivatives with an annulated saturated five membered ring did not yield the desired products, probably due to the reported instability of the corresponding hydroperoxide. ${ }^{17}$

Aniline-substituted tetrahydrocarbazole derivatives are effective as antiviral agents or in cancer treatment. ${ }^{15,18}$ Using method B, we could directly synthesize compounds 25-28, which are highly pharmaceutically active against human papilloma virus ${ }^{18 a}$ and hepatitis C virus ${ }^{18 b}$ or inhibit the vascular endothelial growth factor (Fig. 1). ${ }^{18 c}$

The exclusive $\mathrm{C}-\mathrm{H}$ amination in 1-position of the tetrahydrocarbazole scaffold can be explained by an acid-catalyzed tautomerization reaction between the imine form of 
<smiles></smiles>

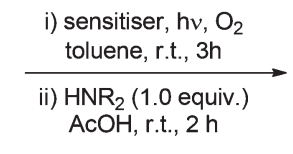<smiles>[R]c1c(C([R])[R16])[nH]c2c([R])cccc12</smiles><smiles>[R]c1ccc(NC2CCCc3c2[nH]c2ccccc32)cc1</smiles>

$\mathrm{R}$

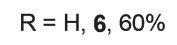

$\mathrm{R}=\mathrm{F}, \mathbf{1 8}, 65 \%$ $\mathrm{R}=\mathrm{COPh}, 19,70 \%$

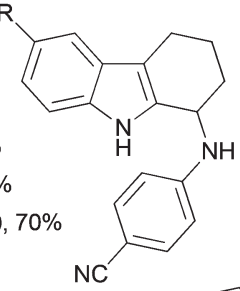

$\mathrm{R}=\mathrm{CN}, 20,50 \%$

$\mathrm{R}=\mathrm{Cl}, \mathbf{2 1}, \mathbf{8 8 \%}$

$\mathrm{R}=\mathrm{Br}, \mathbf{2 2}, 80 \%$
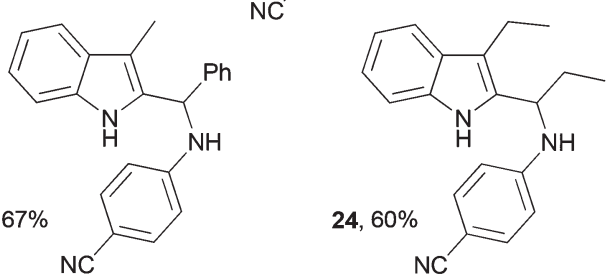

Scheme 4 Product scope of the reaction using method B (see Table 1 for the conditions).

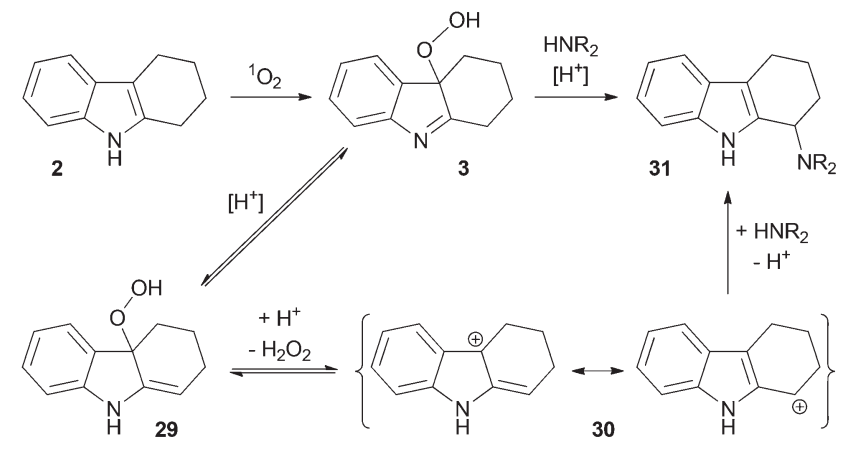

Scheme 5 Proposed mechanism of the $\mathrm{C}-\mathrm{H}$ amination and regiochemistry of $\mathrm{C}-\mathrm{N}$ bond formation by acid catalyzed tautomerization between imine $\mathbf{3}$ and enamine 29

hydroperoxide 3 and its enamine isomer 29 (Scheme 5). Protonation of the hydroperoxide group and loss of hydrogen peroxide would result in a stabilized allylic cation 30, which can be trapped by the $\mathrm{N}$-nucleophile, furnishing exclusively the thermodynamically preferred rearomatized product 31 .

\section{Conclusion}

We have developed a practical method for the $\mathrm{C}-\mathrm{H}$ amination of tetrahydrocarbazole derivatives via intermediate hydroperoxides with the aid of oxygen, visible light and catalytic amounts of a cheap Brønsted acid and a sensitizer. The reaction can be run in two steps or in a one-pot fashion, does not require elevated temperatures or protective groups and can afford the coupling products in high yields within 5-6 hours. The reaction has been applied to the synthesis of some representative pharmaceutically active compounds. The strategy to functionalize $\mathrm{C}-\mathrm{H}$ bonds via substitution of intermediate peroxides formed by the action of oxygen holds great potential for sustainable chemistry and should be applicable to a variety of different substrate classes. Further investigation into the reaction mechanism and extension of this method to access other synthetically interesting products are now the focus of our ongoing efforts.

\section{Experimental}

\section{General}

Except where indicated otherwise, all the reagents and solvents were purchased from commercial sources and used as received. All reactions and work-up procedures were conducted under air except where noted otherwise.

\section{Synthesis of starting materials}

The different tetrahydrocarbazole and indole derivatives were synthesized by Fischer Indole Synthesis using standard procedures. ${ }^{19}$

\section{General procedure for the synthesis of hydroperoxides ${ }^{14 j}$}

The indole derivative $(1 \mathrm{~g})$ was dissolved in toluene $(100 \mathrm{ml})$. To this solution was added rose bengal $(2 \mathrm{mg})$. The resultant reaction mixture was irradiated with a 23 watt lamp under an atmosphere of $\mathrm{O}_{2}$. The progress of the reaction was controlled by ${ }^{1} \mathrm{H}$ NMR. After full conversion of the substrate, the precipitated solid was filtered to afford the desired product in quantitative yields.

\section{General procedures for the reaction of hydroperoxides with N-H nucleophiles}

Method A ( $\left.\mathbf{M e O H}-\mathbf{C F}_{3} \mathbf{C O}_{2} \mathbf{H}\right)$. The hydroperoxide (0.49 mmol, 1.0 equiv.) was dissolved in methanol $(0.5 \mathrm{ml})$. To this reaction mixture was added the desired nucleophile $(0.49 \mathrm{mmol}$, 1.0 equiv.) followed by the addition of $\mathrm{CF}_{3} \mathrm{CO}_{2} \mathrm{H}(3.7 \mu \mathrm{L}$, $0.049 \mathrm{mmol}, 0.1$ equiv.). After $2-4 \mathrm{~h}$, the solvent was reduced to dryness and the resulting solid was purified by column chromatography or by recrystallization.

Method B (AcOH). The hydroperoxide $(0.49 \mathrm{mmol}$, 1.0 equiv.) was dissolved in acetic acid $(0.5 \mathrm{ml})$. To this reaction mixture was added the desired nucleophile $(0.49 \mathrm{mmol}$, 1.0 equiv.). After 2-4 h, the solvent was reduced to dryness and the resulting solid was purified by column chromatography or by recrystallization.

One-pot method with exchange of the solvent. After the synthesis of the peroxide according to the procedure described above, toluene is removed under vacuum and the resulting mixture is directly employed in the next step.

One-pot method without change of the solvent. The indole derivative $(0.49 \mathrm{mmol})$ was dissolved in methanol $(10 \mathrm{ml})$. To this solution was added phthalocyanine $(2 \mathrm{mg})$. The resultant reaction mixture was irradiated with a 500 watt lamp under an atmosphere of oxygen for 40 hours at $-40{ }^{\circ} \mathrm{C}$. The progress of the reaction was controlled by ${ }^{1} \mathrm{H}$ NMR. After full conversion of the substrate, the aniline nucleophile (1.0 equiv.) and $\mathrm{CF}_{3} \mathrm{CO}_{2} \mathrm{H}(10 \mathrm{~mol} \%)$ were added and the mixture was stirred at 
ambient temperature. After 3 hours, the solvent was reduced to dryness and the resulting solid was purified by column chromatography or by recrystallization.

\section{Acknowledgements}

Financial support from the DFG (Heisenberg scholarship to M.K., KL 2221/4-1; KL 2221/3-1), the MPI für Kohlenforschung and Prof. Benjamin List is gratefully acknowledged. We thank Dr Christophe Farès, Prof. Christian W. Lehmann and his team for their assistance with NMR and X-ray and Dr Kevin Jones and Corinna Schmitz for help with the synthesis of some products.

\section{Notes and references}

1 R. G. Bergman, Nature, 2007, 446, 391-393.

2 (a) C. S. Yeung and V. M. Dong, Chem. Rev., 2011, 111, 1215-1292; (b) C. Liu, H. Zhang, W. Shi and A. Lei, Chem. Rev., 2011, 111, 1780-1824; (c) M. Klussmann and D. Sureshkumar, Synthesis, 2011, 353-369; (d) W.-J. Yoo and C.-J. Li, Top. Curr. Chem., 2010, 292, 281-302; (e) A. R. Dick and M. S. Sanford, Tetrahedron, 2006, 62, 2439-2463; ( f) F. Collet, R. H. Dodd and P. Dauban, Chem. Commun., 2009, 5061-5064; $(g)$ R. Rohlmann and O. G. Mancheño, Synlett, 2013, 6-10.

3 (a) P. Anastas and N. Eghbali, Chem. Soc. Rev., 2010, 39, 301-312; (b) C.-J. Li and B. M. Trost, Proc. Natl. Acad. Sci. U. S. A., 2008, 105, 13197-13202.

4 (a) I. Hermans, J. Peeters and P. A. Jacobs, Top. Catal., 2008, 50, 124-132; (b) N. A. Milas, Chem. Rev., 1932, 10, 295-364.

5 (a) Á. Pintér, A. Sud, D. Sureshkumar and M. Klussmann, Angew. Chem., Int. Ed., 2010, 49, 5004-5007; (b) Á. Pintér and M. Klussmann, Adv. Synth. Catal., 2012, 354, 701-711.

6 B. Schweitzer-Chaput and M. Klussmann, Eur. J. Org. Chem., 2013, 666-671.

7 For related reactions, see: (a) C. W. Jefford, J. C. Rossier, S. Kohmoto and J. Boukouvalas, Helv. Chim. Acta, 1985, 68, 1804-1814; (b) I. Saito, H. Nakagawa, Y. H. Kuo, K. Obata and T. Matsuura, J. Am. Chem. Soc., 1985, 107, 5279-5280; (c) B. Zhang, S.-K. Xiang, L. H. Zhang, Y. Cui and N. Jiao, Org. Lett., 2011, 13, 5212-5215; (d) C. G. Piscopo, S. Buhler, G. Sartori and R. Maggi, Catal. Sci. Technol., 2012, 2, 24492452; (e) H. Gunduz, V. Kumbaraci and N. Talinli, Synlett, 2012, 2473-2476; (f) N. Jiao, B. Zhang and Y. Cui, Chem. Commun., 2012, 48, 4498-4500.

8 H. Hock and S. Lang, Ber., 1944, 77, 257-264.

9 (a) L. Liguori, H.-R. Bjorsvik, F. Fontana, D. Bosco, L. Galimberti and F. Minisci, J. Org. Chem., 1999, 64, 88128815; (b) P. H. Dussault, H.-J. Lee and X. Liu, J. Chem. Soc., Perkin Trans. 1, 2000, 3006-3013.

10 (a) S.-I. Murahashi, T. Naota and K. Yonemura, J. Am. Chem. Soc., 1988, 110, 8256-8258; (b) S.-I. Murahashi,
T. Naota, T. Kuwabara, T. Saito, H. Kumobayashi and S. Akutagawa, J. Am. Chem. Soc., 1990, 112, 7820-7822; (c) A. G. Davies, R. V. Foster and R. Nery, J. Chem. Soc., 1954, 2204-2209.

11 (a) M. Ishikura, K. Yamada and T. Abe, Nat. Prod. Rep., 2010, 27, 1630-1680; (b) M. Ishikura and K. Yamada, Nat. Prod. Rep., 2009, 26, 803-852; (c) D. Liu, G. Zhao and L. Xiang, Eur. J. Org. Chem., 2010, 3975-3984.

12 (a) R. J. S. Beer, L. McGrath, A. Robertson and A. B. Woodier, Nature, 1949, 164, 362-363; (b) M. R. Iesce, F. Cermola and F. Temussi, Curr. Org. Chem., 2005, 9, 109-139.

13 H. H. Wasserman and J. L. Ives, Tetrahedron, 1981, 37, 1825-1852.

14 For a review, see: (a) M. Mentel and R. Breinbauer, Curr. Org. Chem., 2007, 11, 159-176; For representative examples, see: (b) S. G. P. Plant and M. L. Tomlinson, J. Chem. Soc., 1950, 2127-2130; (c) R. J. S. Beer, L. McGrath and A. Robertson, J. Chem. Soc., 1950, 2118-2126; (d) B. Witkop and J. B. Patrick, J. Am. Chem. Soc., 1951, 73, 2188-2195; (e) E. Leete, J. Am. Chem. Soc., 1961, 83, 3645-3647; (f) F. Ying-Hsiueh Chen and E. Leete, Tetrahedron Lett., 1963, 4, 2013-2017; (g) S. McLean and G. I. Dmitrienko, Can. J. Chem., 1971, 49, 3642-3647; (h) E. Winterfeldt, Liebigs Ann. Chem., 1971, 745, 23-30; (i) T. Itahara, H. Ouya and K. Kozono, Bull. Chem. Soc. Jpn., 1982, 55, 3861-3864; (j) C. A. Mateo, A. Urrutia, J. G. Rodríguez, I. Fonseca and F. H. Cano, J. Org. Chem., 1996, 61, 810-812.

15 (a) S. Mahboobi, S. Kuhr and W. Meindl, Arch. Pharm., 1994, 327, 611-617; (b) J. D. Ha, S. K. Kang, H.-G. Cheon and J.-K. Choi, Bull. Korean Chem. Soc., 2004, 25, 17841790; (c) K. S. Gudmundsson, S. D. Boggs, P. R. Sebahar, L. D. A. Richardson, A. Spaltenstein, P. Golden, P. B. Sethna, K. W. Brown, K. Moniri, R. Harvey and K. R. Romines, Bioorg. Med. Chem. Lett., 2009, 19, 4110-4114.

16 (a) K. Higuchi, M. Tayu and T. Kawasaki, Chem. Commun., 2011, 47, 6728-6730; (b) H. Zaimoku, T. Hatta, T. Taniguchi and H. Ishibashi, Org. Lett., 2012, 14, 6088-6091; (c) R. J. Owellen, J. Org. Chem., 1974, 39, 69-72; (d) C. Chan, C. Li, F. Zhang and S. J. Danishefsky, Tetrahedron Lett., 2006, 47, 4839-4841; (e) R. E. Ziegler, S.-J. Tan, T.-S. Kam and J. A. Porco, Angew. Chem., Int. Ed., 2012, 51, 9348-9351; (f) M. Aiura and Y. Kanaoka, Heterocycles, 1974, 2, 319-322.

17 B. Witkop, J. B. Patrick and M. Rosenblum, J. Am. Chem. Soc., 1951, 73, 2641-2647.

18 (a) S. D. Boggs, K. S. Gudmundsson, L. D. A. Richardson and P. R. Sebahar, Tetrahydrocarbazole derivatives and their pharmaceutical use. USA Pat., WO 2004/110999 A1, 2004; (b) K. S. Gudmundsson, HCV Inhibitors, USA Pat., WO 2006/121467 A2, 2006; (c) W. J. Lennox, H. Qi, D.-H. Lee, S. Choi and Y.-C. Moon, Tetrahydrocarbazoles as active agents for inhibiting VEGF production by translational control. USA Pat., WO 2006/065480 A2, 2006.

19 (a) P. P. Varma, B. S. Sherigara, K. M. Mahadevan and V. Hulikal, Synth. Commun., 2008, 39, 158-165; (b) W. Stadlbauer, H. Van Dang and B. S. Berger, J. Heterocycl. Chem., 2010, 47, 807-824. 